\title{
Multidisciplinary Management of Primary Sacral Tumors: A Tertiary Care Center's Experience and Literature Review
}

\author{
Venugopal Sarath Chander ${ }^{1,2}$, Ramachandran Govindasamy ${ }^{1,2}$, \\ Venkata Ramakrishna Tukkapuram $^{1,2}$, Swaroop Gopal ${ }^{1,2}$, Satish Rudrappa ${ }^{1,2}$ \\ ${ }^{1}$ Institute of Neurosciences, Sakra World Hospital, Bangalore, India \\ ${ }^{2}$ Department of Spine Surgery, Sakra World Hospital, Bangalore, India
}

\begin{abstract}
Sacral tumors are rare and can be benign or malignant. Their management is multifactorial and is based on the pathology, extent, and local and distant spread. Managing sacral tumors is challenging due to their proximity to visceral and neural structures. Surgical wide excision has been the standard of care for aggressive benign and malignant tumors. Our purpose was to evaluate the outcomes of a multimodal approach to managing primary sacral tumors in Sakra World Hospital, a tertiary spine care center in Bengaluru, India and perform a literature review to determine a workflow pathway. Our study was a retrospective review of patient records and included 15 patients with primary sacral tumors. Eleven surgically treated patients were evaluated clinically and radiologically and underwent biopsy before surgical excision by an all-posterior approach. A multidisciplinary approach that included intraoperative neural monitoring, plastic reconstruction, adjuvant chemotherapy, and radiotherapy was implemented whenever necessary. Sacral root preservation was attempted whenever feasible. Functional outcomes (based on the Visual Analog Scale [VAS] and Biagini scoring system) were analyzed along with disease control, with a minimum of 2 years of follow-up. The mean follow-up was $29 \pm 9.8$ months. The mean VAS score significantly improved from $7.8 \pm 2.6$ to $3.7 \pm 3.8(p=0.026)$. Bowel function showed statistically significant improvement, from a mean score of $0.81 \pm 0.47$ to $0.63 \pm 0.52(p=0.026)$ at 2 years of follow-up. The mean pretreatment motor and bladder function scores were $0.53 \pm 0.31$ and $0.74 \pm 0.44$, respectively, improving to $0.48 \pm 0.33$ and $0.68 \pm 0.56$ at follow-up but without statistical significance. There was no significant loss of function, which is expected in radical sacral resections. In conclusion, primary sacral tumors require a multidisciplinary approach and management for optimal outcomes. A stand-alone posterior approach can be employed to treat most sacral lesions. En-bloc wide resection is the optimal treatment for primary malignant and aggressive benign tumors. Preservation of at least one functional S2 nerve root is imperative to preserve bowel and bladder function.
\end{abstract}

Keywords: Sacral tumors; Sacrectomy; Posterior approach; Literature review

\section{Introduction}

Primary tumors of the sacrum are very rare entities, con- stituting approximately $1 \%-7 \%$ of primary spinal tumors, which in turn constitute only a mere $10 \%$ of primary bone tumors [1]. Low-grade primary tumors are often diag-

\footnotetext{
Received Apr 17, 2021; Revised May 27, 2021; Accepted Jun 8, 2021

Corresponding author: Satish Rudrappa

Department of Spine Surgery, Institue of Neurosciences, Sakra World Hospital, Bellandur, Bangalore, India

Tel: +91-9844020211, Fax: +91-80-4969-4969, E-mail: drsatishr@gmail.com
} 
nosed late, owing to their clinical resemblance to degenerative lumbar spine disorders, while high-grade tumors might have an early and a more dramatic presentation $[1,2]$. Primary sacral tumors can be benign or malignant and, based on their origin, can be predominantly grouped as primary osseous or primary neurogenic. The most common malignant sacral lesions are chordomas, which are low-grade tumors, whereas the most common benign lesions are giant cell tumors (GCT), which are locally aggressive and potentially recurrent [2].

The management of these tumors is based on numerous factors, such as tumor pathology, the upper limit of the tumor extent, involvement of neural structures, and distant metastasis [3]. Nevertheless, surgery remains the cornerstone for treating nonmetastatic primary sacral tumors [1-4]. The complex sacral anatomy, including the neural structures, adjacent visceral relationships, biomechanical role in load transmission, and late presentation of sacral tumors often poses a surgical challenge, making the surgery a multidisciplinary affair. These operations were once considered long, bloody, and morbid procedures; however, a multidisciplinary approach and recent advances have helped achieve significant breakthroughs in the treatment paradigm of primary sacral tumors. Aggressive sacral resections can cause varying degrees of neurological (bladder, bowel, motor, and sexual) dysfunction based on the level $[1,5]$. In the end, achieving good disease control and minimizing neurological complications are paramount in reaching positive treatment outcomes.

In our study, we present a group of 15 patients with primary sacral tumors that include bony tumors, neural tumors, and sarcomas, which were treated accordingly. Based on a literature review and our experience, we propose a protocol for managing primary sacral tumors entailing a multidisciplinary approach.

\section{Single Institution Experience of Primary Sacral Tumors}

We studied the case records of patients with primary sacral tumors treated between 2011 and 2020 in Sakra World Hospital, Bengaluru, India which is a tertiary spine care center, a tertiary spine care center. We included case records only of patients with a minimum 2-year followup. Patients with sacral lesions that were ultimately infections and metastatic lesions were excluded, given these cases were beyond the scope of our study. Ultimately, 15 patients were included, and their medical records, radiological images, and pathology reports were retrospectively reviewed. Given that the study was conducted using only the patients' in-patient and follow-up records, ethical approval for the study was waived.

All of our patients had undergone a uniform management protocol starting with a thorough neurological and clinical (including per rectal) examination, which was followed by X-rays, computed tomography (CT) and magnetic resonance imaging (MRI) to assess soft tissue extension. Positron emission tomography (PET) CT was also performed to search for distant metastasis when necessary. A percutaneous CT-guided biopsy of the lesion was performed by our interventional radiology team with the patient under local anesthesia to obtain a histological diagnosis. After the investigations had been concluded, the management was planned based on (1) the clinical presentation, especially neurological dysfunction; (2) the tumor pathology, as per the histopathological examination; (3) the upper extent of the lesion (MRI); (4) the soft tissue extent and local invasion of adjacent structures (MRI); and (5) the presence of metastasis (PET). All cases were subjected to a tumor board review comprising the treating surgeon, radiologist, pathologist, medical oncologist, plastic surgeon, urologist, and radiation oncologist for the decision-making process regarding treatment. Radiotherapy or chemotherapy was administered for inoperable advanced malignant lesions.

Clear surgical principles were considered for all cases, which included (1) an all-posterior approach; (2) sacrectomy with wide excision to achieve clear margins to minimize recurrence; (3) preservation of S1 and sacroiliac joint integrity to prevent lumbopelvic fixation, if possible (except in one case in which S1 was removed to achieve wide excision); (4) preservation of at least one S2 nerve root to preserve bladder function; and (5) plastic reconstruction with advancement flaps when necessary. Neural tumors were treated by laminectomy and lesion excision. Regardless of the sacrectomy level, neural dissection was started at L5-S1 through a laminectomy and traced distally to preserve at least one functional S2 nerve root (Fig. 1A-D). The functional status of the nerve roots was identified using triggered electromyography of the foot muscles and anal sphincter muscles, a component of intraoperative neural monitoring. Seeding of tumor tissue was avoided by total excision of the tumor and excision of the biopsy tract after its identification by methylene blue 

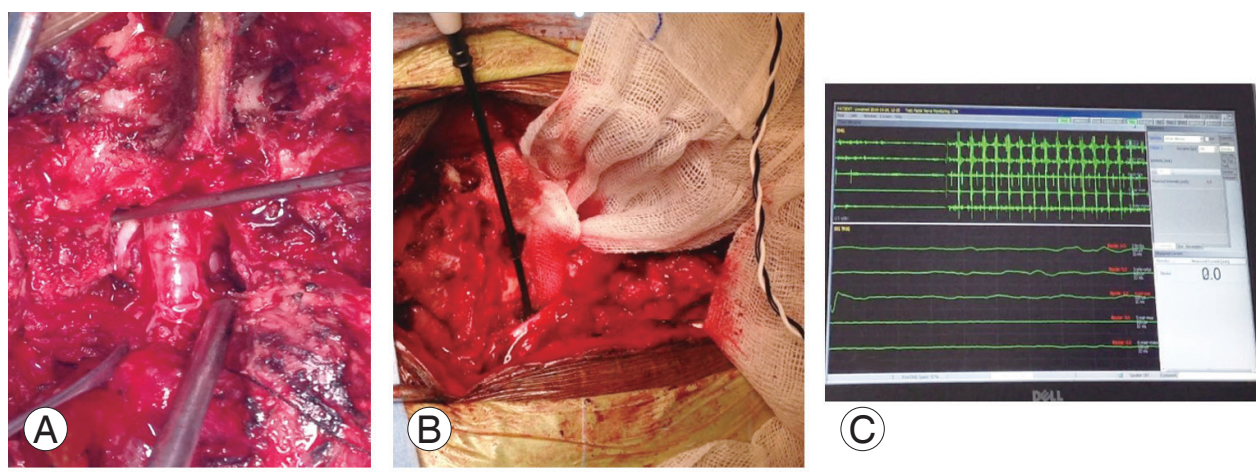

(C)
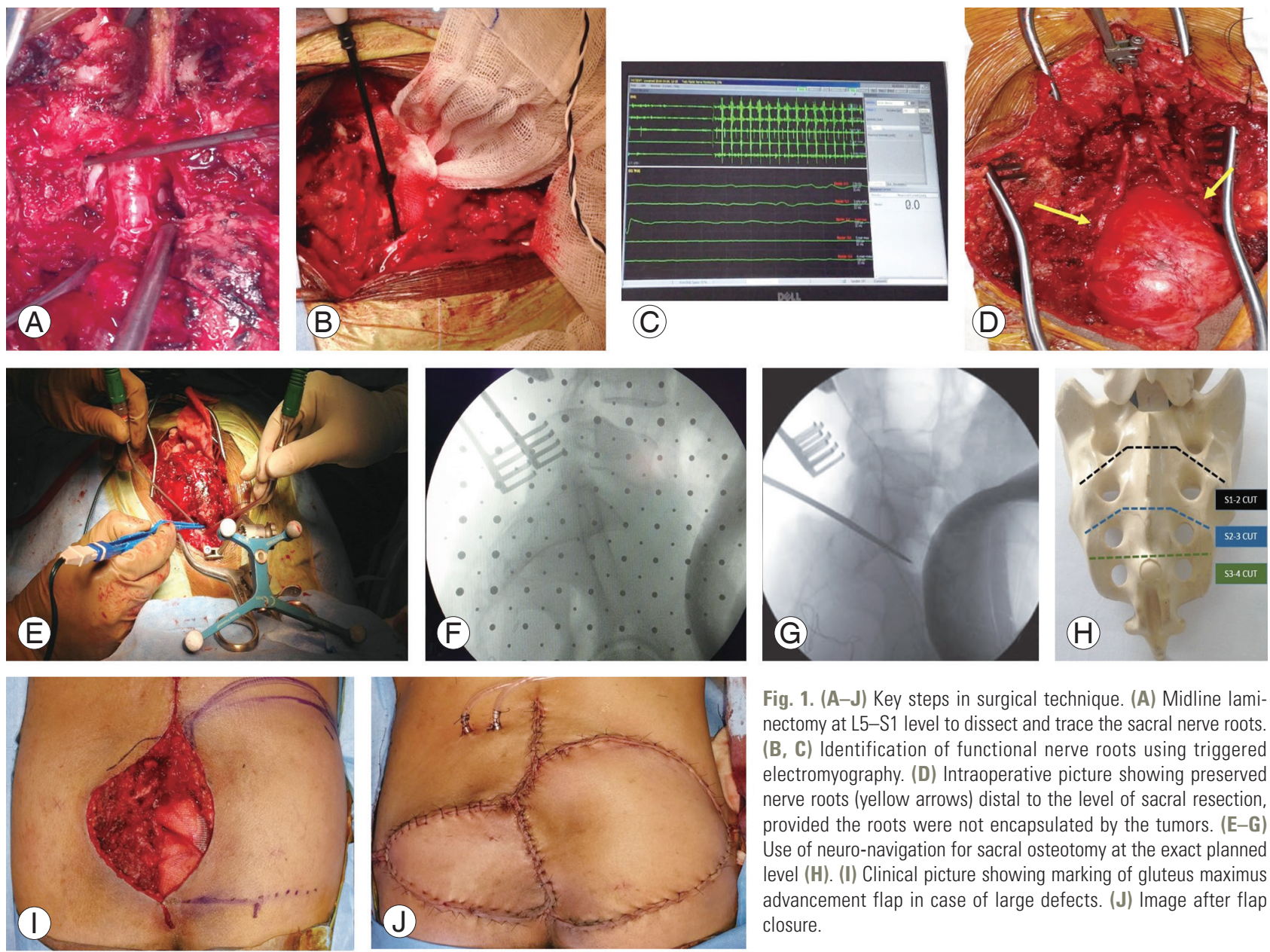

Fig. 1. (A-J) Key steps in surgical technique. (A) Midline laminectomy at L5-S1 level to dissect and trace the sacral nerve roots. (B, C) Identification of functional nerve roots using triggered electromyography. (D) Intraoperative picture showing preserved nerve roots (yellow arrows) distal to the level of sacral resection, provided the roots were not encapsulated by the tumors. (E-G) Use of neuro-navigation for sacral osteotomy at the exact planned level (H). (I) Clinical picture showing marking of gluteus maximus advancement flap in case of large defects. (J) Image after flap closure.

injection. Preoperatively, cytoreduction was attempted in chemosensitive tumors such as Ewing's sarcoma (ES). Digital subtraction angiography (DSA) followed by a preoperative transarterial embolization (TAE) in hypervascular tumors such as GCTs was performed to reduce blood loss.

Prophylactic antibiotic prophylaxis was with $1 \mathrm{~g}$ intravenous ceftriaxone administered 30 minutes prior to the surgical procedure and was repeated every 4 hours if necessary. Intraoperative blood loss was reduced by the usage of tranexamic acid infusion in patients who could not tolerate significant blood loss. Neuro-navigation was utilized to perform an accurate sacral resection at the planned level (Fig. 1E-H). The plastic surgery team was involved in cases of large skin or soft tissue defects to plan and perform an appropriate flap cover (Fig. 1I, J). Postoperatively, the same antibiotic was continued intravenously until the day of surgical site drain removal after wound inspection.
Follow-up records of patients at 1 month, 6 months, 1 year, and 2 years were reviewed along with their respective radiological images. Treatment outcomes considered in our study were (1) functional outcome (pain-related disability and neurological function) before and after treatment; and (2) disease control (recurrence and metastasis) after completion of treatment. The Visual Analog Scale was used to assess pain-related disability. The assessment of neurological function, including motor, bladder, and bowel function scoring, was as adapted from Biagini et al. [6] and is shown in Table 1.

The continuous variables are expressed as mean \pm standard deviation and the categorical variables as frequencies and percentages. For comparison analysis, the Wilcoxon signed rank test was used due to the non-normal data distribution. The data were analyzed using IBM SPSS ver. 21.0 (IBM Corp., Armonk, NY, USA).

The characteristics of all 15 cases included in our study 
Table 1. Classification of neurologic function after resection of the sacrum

\begin{tabular}{lll} 
Function & 0 & Normal \\
Bladder & 1 & $\begin{array}{r}\text { Feels stimulus to micturate and has limited continence at varying times and quantities of urine and/or has increasing postmicturi- } \\
\text { tion vesical residual and/or urinary loss in conditions of stress }\end{array}$ \\
\hline Bowel & 2 & Does not feel stimulus to micturate and/or is completely incontinent \\
\hline Motor & 0 & Normal \\
& 1 & Feels stimulus to defecate and is incontinent when feces are soft or under stress \\
\hline & 0 & Does not feel stimulus to defecate and/or is completely incontinent \\
\hline & 1 & Deficits requiring the help of external support for walking and common activities \\
\hline
\end{tabular}

Adapted from Biagini et al. Chir Organi Mov 1997;82:357-72 [6].

are shown in Table 2. A total of 15 patients with primary sacral tumors were reviewed, of which 10 were men and five were women. Two patients had extracompartmental recurrent chordomas after prior surgery elsewhere. All 15 patients had back pain as a presenting symptom; six had radicular symptoms or signs; five had bladder and bowel dysfunction. The most common diagnosis was chordoma $(\mathrm{n}=7)$. The proximal extent of lesions was up to $\mathrm{S} 1 \mathrm{in}$ four patients. However, only two were surgically treated. A total of 11 patients underwent surgery, including eight partial sacrectomies (without any instrumentation), one total sacrectomy (GCT involving S1) with lumbopelvic fixation and two patients with neural tumors treated with laminectomy and tumor excision. The average duration of surgery was 6.5 hours, with a mean blood loss of approximately $900 \mathrm{~mL}$. The patient with a GCT underwent wide excision after TAE considering the aggressive nature and potential recurrence. One patient with ES received neoadjuvant chemotherapy (NAC) and underwent partial sacrectomy after cytoreduction. Four patients were treated with chemotherapy (one non-Hodgkin lymphoma; one adenocarcinoma; chemotherapy with radiotherapy in one case of inoperable ES; and NAC in one operable ES). Two inoperable patients underwent radiotherapy, which included one recurrent chordoma and one ES. One patient with mucinous cystadenoma had to undergo an additional anterior procedure and colostomy.

The mean follow-up was $29 \pm 9.8$ months. Of eight patients who underwent partial sacrectomy (without additional stabilization), seven patients had no stability-related complications. One patient in whom the sacral cut was taken through the S1 body had an S1 stress fracture in follow-up and could be managed conservatively. Only one patient (out of five) who had preoperative bladder and bowel dysfunction regained reasonable function post-surgery, whereas the remaining four patients had no recovery and were taught self-intermittent catheterization. None $(n=11)$ of the patients who had intact bowel and bladder function preoperatively worsened post-treatment. Two patients had postoperative surgical site infection, among which one patient needed debridement. One patient with recurrent chordoma had a second recurrence after partial sacrectomy surgery. Two patients (one with adenocarcinoma and one with mucinous cystadenocarcinoma) had a distant spread at the last follow-up and was followed up with chemotherapy. One patient with ES (treated with NAC and partial sacrectomy) developed pneumonia following a compromised immune status and ultimately succumbed to systemic sepsis. The results of our study have been summarized (Tables 3, 4).

\section{Literature Review}

Primary sacral tumors are rare, accounting for approximately $1 \%-7 \%$ of primary spinal tumors [1]. The majority of sacral tumors are metastatic lesions from breast, prostate, lung, or colon carcinomas [1], and their therapeutic approach differs completely from primary tumors [2]. Primary tumors can be classified based on their origin as osseous, neural (e.g., schwannoma), notochordal (e.g., chordoma), primitive neuroectodermal (PNET) (e.g., ES), hematopoietic (e.g., lymphoma, myeloma), and tumor-like (e.g., aneurysmal bone cyst) [2]. They can also be grouped into benign and malignant tumors. The most common 


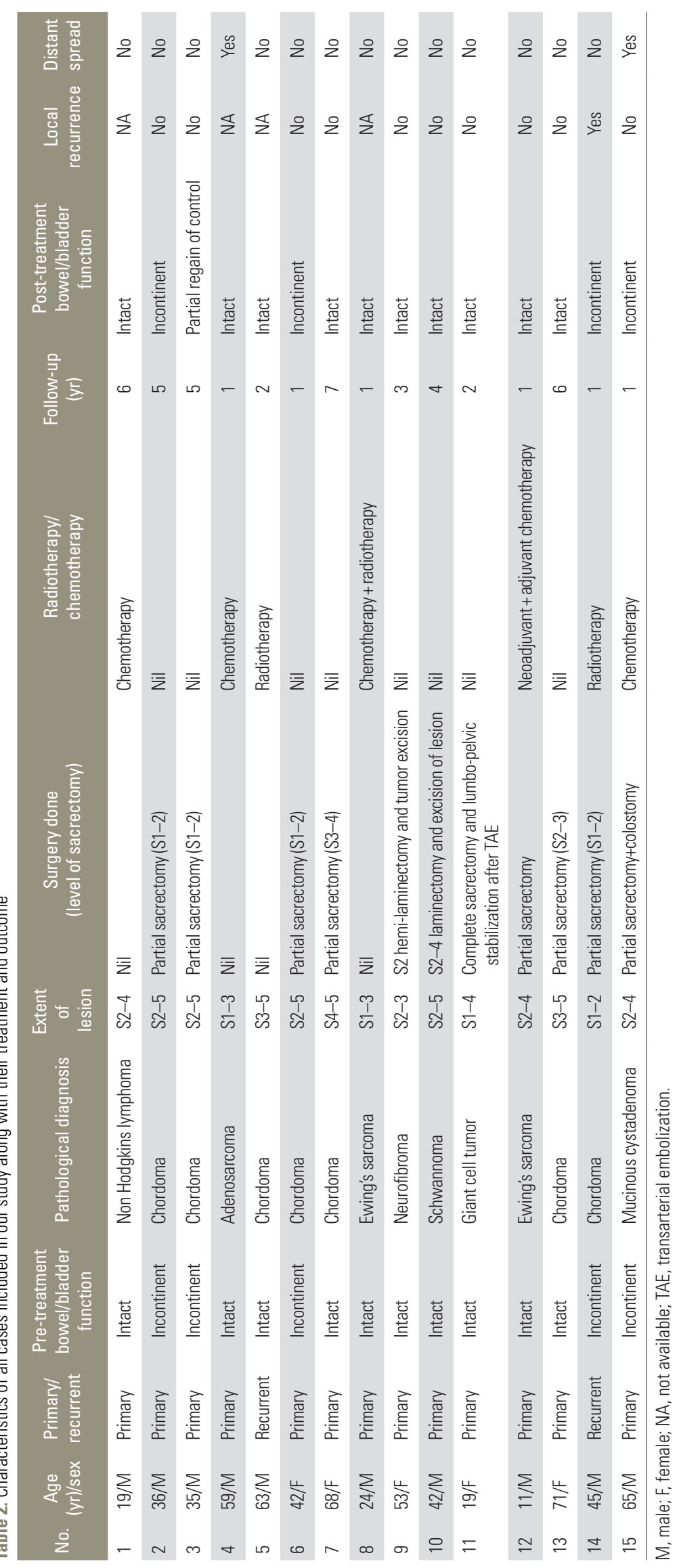


malignant tumor of the sacrum is chordoma, followed by chondrosarcoma, myeloma, malignant nerve sheath tumors, ES, and lymphoma [2,5]. The common benign tumors include GCTs, schwannomas, and aneurysmal bone cysts. However not all benign tumors are low-grade lesions; e.g., GCTs, which can be locally aggressive. Hence, more usefully, the primary tumors can be grouped as (1) low-grade tumors (chordoma, chondrosarcoma), which are slow-growing with nonspecific clinical symptoms; and (2) high-grade tumors, such as ES, osteosarcoma, and GCT, which can have a more aggressive clinical presentation and recurrence [3]. As reported in the literature, chordoma was the most common primary tumor in our study (seven cases), followed by primary neural tumors and ES (two cases each).

MRI followed by CT is the most informative radiological investigation, given it provides a host of information, such as the possible epicenter of the lesion, presence of soft tissue matrix, probable tumor pathology, and most importantly the extent of tumor, which primarily dictates the level of sacral resection to be planned in cases need- ing a wide excision [1,7]. PET scan could be an important prognostication tool to opt between a curative treatment or a palliative treatment based on distant metastasis [7]. Given the pathology is the most decisive factor determining the prognosis and treatment of sacral lesions, CTguided biopsy is a critical component in their diagnostic algorithm. Safaee et al. [8] reported a positive biopsy in up to $95 \%$ of sacral lesions, with correlation rates approaching $100 \%$. Excision of the biopsy tract following CT-guided biopsy is less likely to cause tumor contamination of the surgical plane compared with open biopsy. We used methylene blue injection for the identification of the biopsy tract in our patients. Primary sacral tumors are treated principally based on four factors: (1) tumor pathology (based on biopsy); (2) the proximal extent of the tumor; (3) neurological dysfunction; and (4) contiguous spread and distant metastasis. The treatment modalities are chemotherapy, radiotherapy, and surgery, with surgery as the cornerstone of curative treatment in nonmetastatic primary tumors [2-4].

Various surgical approaches have been employed for

Table 3. Functional outcome of patients comparing pain and neurological status before and after treatment

\begin{tabular}{lccc} 
Variable & Pre-treatment & 2-Year follow-up & $p$-value \\
\hline Visual Analog Scale score & $7.8(5-10)$ & $3.7(2-7)$ & $0.026^{*}$ \\
Motor function $(0-2)^{\text {a) }}$ & $0.53 \pm 0.31$ & $0.48 \pm 0.33$ & 0.125 \\
\hline Bladder function (0-2) & $0.74 \pm 0.44$ & $0.68 \pm 0.56$ & 0.059 \\
\hline Bowel function (0-2) & $0.81 \pm 0.47$ & $0.63 \pm 0.52$ & $0.026^{*}$ \\
\hline
\end{tabular}

Values are presented as mean (range) or mean \pm standard deviation.

${ }^{*} p<0.05$ (statistically significant). ${ }^{\text {a) }}$ Classification of neurological function as adapted from Biagini et al. [6].

Table 4. Complications and disease control at 2-year follow-up

\begin{tabular}{lcc} 
Variable & No & Yes \\
\hline Postoperative sacral stress fracture $(n=11)$ & $10(91)$ & $1(9)$ \\
Surgical site infection $(n=11)$ & $9(82)$ & $2(18)$ \\
Local recurrence $(n=15)$ & $13(87)$ & $2(13)$ \\
Distant metastasis $(n=15)$ & $13(87)$ & $2(13)$ \\
Survival at 2 years $(n=15)$ & $1(7)$ & $14(93)$ \\
\hline
\end{tabular}

Values are presented as number (\%).

Table 5. Review of the literature of various studies employing posterior approach for sacrectomy

\begin{tabular}{|c|c|c|c|}
\hline Study & No. of cases & Indications & Modifications \\
\hline Gennari et al. [12] (1987) & 8 & Lesions below S2 & Not specified \\
\hline Waisman et al. [13] (1997) & 5 & Sacral tumors without local visceral spread & Usage of mersilene mesh to prevent herniation \\
\hline McLoughlin et al. [15] (2008) & 1 & Not specified & $\begin{array}{l}\text { En-bloc total sacrectomy done by lifting the sacrum from proximal } \\
\text { to distal and anterior dissection }\end{array}$ \\
\hline Asavamongkolkul et al. [14] (2012) & 21 & For all sacral lesions as high as $\mathrm{L} 5$ & $\begin{array}{l}\text { Large amount of gauze packing anterior to sacrum for blunt dis- } \\
\text { section and protection during osteotomy }\end{array}$ \\
\hline Clarke et al. [9] (2012) & 36 & $\begin{array}{l}\text { All tumors not extending beyond the lumbo- } \\
\text { sacral junction or invading the bowel }\end{array}$ & Not specified \\
\hline Zang et al. [16] (2015) & 10 & $\begin{array}{l}\text { High sacral lesions without local anterior } \\
\text { invasion }\end{array}$ & Use of wire saw for ilium cutting from inside to outside \\
\hline Our study & 11 & $\begin{array}{l}\text { All sacral lesions (as high as L5-S1) with no } \\
\text { local invasion of anterior structures }\end{array}$ & $\begin{array}{l}\text { Division of ligaments, lifting of sacrum en-bloc from distal to } \\
\text { proximal, anterior blunt dissection }\end{array}$ \\
\hline
\end{tabular}


sacral resections. Conventionally, total and high sacrectomies have been performed via combined anterior-posterior approaches [9-11]. The stand-alone posterior approach was initially advocated for distal sacral resections [12] and was later extended to en-bloc total sacrectomy with a few modifications by many authors $[9,13-16]$. The various literature discussing the applicability of an all-posterior approach has been listed (Table 5). The feasibility of an allposterior surgical approach for sacrectomies is based on the anterior extent, proximal limit, and accessibility of the tumor $[9,16]$. An all-posterior approach has been shown to have lesser morbidity and blood loss compared with the combined approach $[9,15,16]$. The surgeries we performed in all the cases with no anterior visceral involvement employed only a posterior approach. The anterior extent of the tumor was preoperatively decided based on per rectal clinical examination and by MRI. We could remove the tumor en bloc even in lesions involved up to S1 employing a stand-alone posterior approach, starting the dissection caudally by division of ligaments and proximal blunt dissection deep to the presacral fascia and mobilization of pelvic structures. One patient in whom the primary lesion was a mucinous cyst adenocarcinoma contiguously involving the colon underwent an additional anterior bowel resection procedure along with a colostomy.

Wide excision with clear margins is the preferred treatment in aggressive benign and malignant tumors. Based on the level of resection, the surgeries have been termed as low, mid, high, hemi, and total sacral resections with predictable degrees of bowel, bladder, and sexual dysfunction $[1,6,17]$. Total sacral resections (involving the S1 body) could also result in lumbopelvic instability and warrant lumbopelvic fixation [18]. An optimal outcome could be obtained by minimizing disease recurrence by balancing a wide excision, concurrently preserving at least the S1 body to maintain stability and a few functional sacral roots contributing to the pudendal nerve to preserve bowel and bladder function. The necessary sacral roots to be preserved for good bowel and bladder function has been debated in the literature (Table 6). Various authors have recommended the preservation of the S3 root [19-26], with few among them reporting good function with preservation of one or more S2 nerve roots [12,17,27-29]. In our patients, irrespective of how high the sacrectomy, functional sacral roots (at least one S2 root) were preserved, provided they were not encased in the tumor seven of 11 surgical patients had intact bowel and bladder function before surgery; as a result of pre-

Table 6. Review of the literature discussing the neurological function post sacral resections and surgical recommendations

\begin{tabular}{|c|c|c|c|}
\hline Study & No. of cases & Results & $\begin{array}{l}\text { Recommendation of } \\
\text { sacral root preservation }\end{array}$ \\
\hline Gunterberg [23] (1976) & 10 & Intactness of at least one S3 preserves normal bladder and anorectal function & Unilateral S3 \\
\hline Stener et al. [27] (1978) & 5 & Functional urinary and fecal continence is possible if $\geq 0 n e ~ S-2$ root can be preserved & Unilateral S2 \\
\hline Andreoli et al. [29] (1986) & 2 & $\begin{array}{l}\text { Retaining one S-2 root is sufficient for the maintenance of physiologic continence of bowel \& } \\
\text { bladder }\end{array}$ & Unilateral S2 \\
\hline Sung et al. [19] (1987) & 54 & Excision below S3 does not affect bowel or bladder function & Unilateral S3 \\
\hline Gennari et al. [12] (1987) & 8 & When both S2 roots were preserved, sphincter problems were mild and reversible & Bilateral S2 \\
\hline Fujimura et al. [28] (1994) & 8 & $\begin{array}{l}\text { Bilateral preservation of } S 2 \text { nerve roots necessary to maintain bowel, bladder \& sexual func- } \\
\text { tion }\end{array}$ & Bilateral S2 \\
\hline Cheng et al. [21] (1999) & 23 & Preservation of B/L S3 roots helped preserve $100 \%$ bowel $\&$ bladder function & Bilateral S3 \\
\hline Bergh et al. [24] (2000) & 30 & S3 nerves appear the most critical determinant of bowel, bladder function & S3 preservation \\
\hline Todd et al. [22] (2002) & 53 & Preservation of B/L S3 roots helped preserve $100 \%$ bowel function, $69 \%$ bladder function & Unilateral S3 \\
\hline Fourney et al. [17] (2005) & 78 & Middle sacrectomy has lesser bladder dysfunction than high sacrectomy & Bilateral S2 \\
\hline Guo et al. [25] (2005) & 50 & $\begin{array}{l}\text { Bowel incontinence incidence was } 37.5 \% \text { after unilateral S-3 nerve root resection and } 75 \% \\
\text { after bilateral resections }\end{array}$ & Bilateral S3 \\
\hline Moran et al. [20] (2015) & 73 & Better bowel, bladder function with low sacrectomy (below S3) & Bilateral S3 \\
\hline Zoccali et al. [26] (2016) & Review & Better bowel and bladder function when S3 nerve root preserved & Unilateral S3 \\
\hline Our study & 11+Review & $\begin{array}{l}\text { Preservation of one functional (by triggered electromyography testing) nerve root preserves } \\
\text { reasonable bowel \& bladder function }\end{array}$ & Unilateral S2 \\
\hline
\end{tabular}



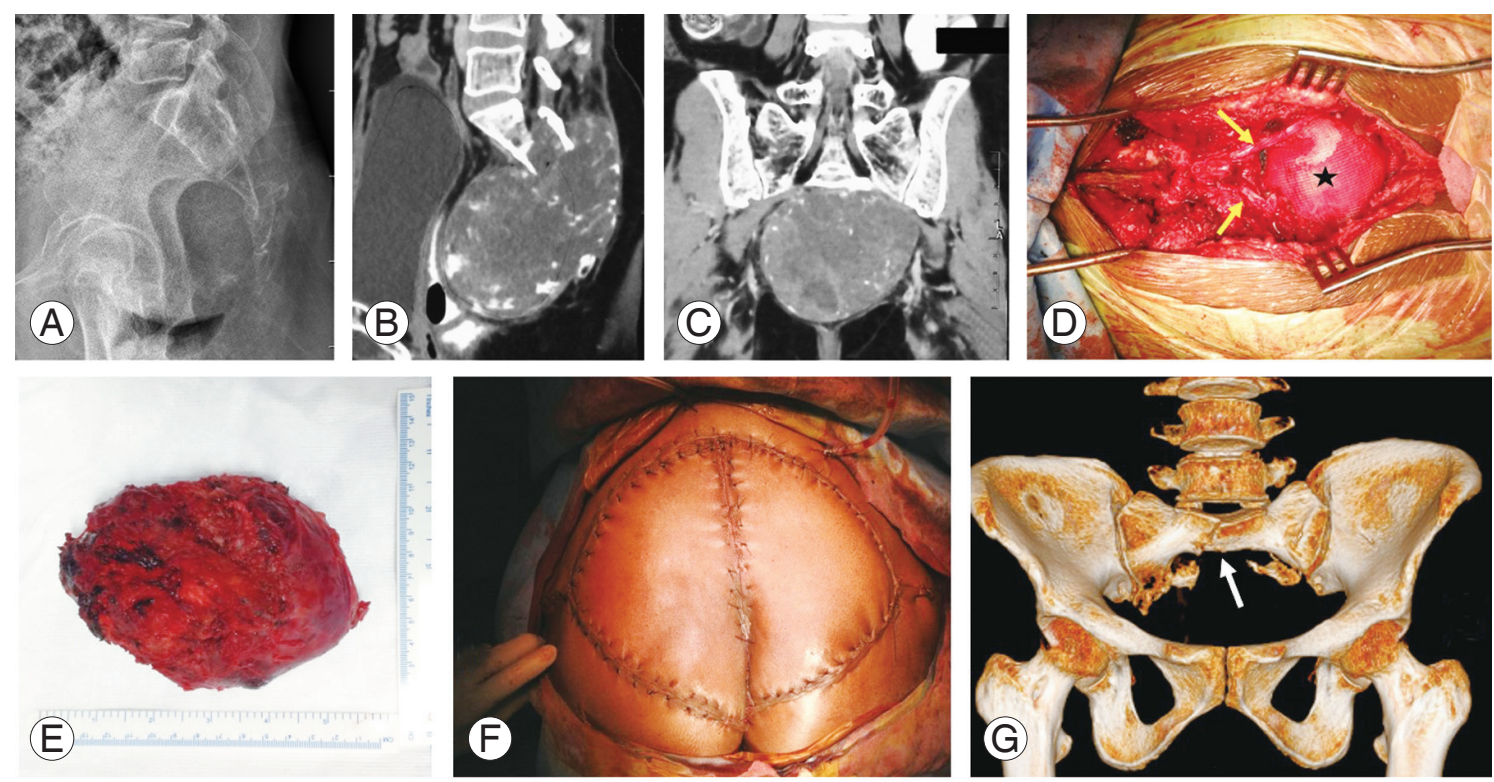

Fig. 2. (A-G) Large sacral chordoma extending up to S1-S2. (A) Preoperative X-ray showing destructive lesion involving the sacrum. (B, C) Preoperative sagittal and coronal computed tomography (CT) images showing the extent of lesion up to S1-S2 with a large encapsulated pre-sacral component. (D) Intraoperative image showing the preserved S2 nerve roots (yellow arrows) and large defect following sacrectomy reconstructed by mesh (black star). (E) Clinical image of specimen resected by wide excision. (F) Plastic reconstruction and closure of large defect by gluteus maximus advancement flap. (G) Follow-up CT scan at 18 months showing a stress fracture involving S1 (white arrow), which was conservatively managed.

serving at least one S2 root, none of them lost bowel or bladder function postoperatively. In our study, of eight patients who underwent partial sacrectomy, one patient (chordoma involved up to S1-S2) in whom the resection was performed through the $\mathrm{S} 1$ body had an insufficiency fracture of redundant $\mathrm{S} 1$ body (Fig. 2), whereas all seven remaining patients had no stability-related pain. The use of neuro-navigation helped in making precise osteotomy cuts where desired without destabilizing the sacroiliac joints, in addition to reducing the operating time and the amount of radiation exposure to the operating room personnel. One patient who underwent a total sacrectomy had additional lumbopelvic fixation.

Preoperative TAE of the feeding vessel after a DSA is known to reduce intraoperative blood loss and surgical time in all vascular sacral tumors [30]. Its effectiveness in treating chordoma and GCT are well reported in the literature [31,32]. We used preoperative TAE in one patient with a GCT extending up to S1, followed by total sacrectomy and reconstruction, which helped reduce intraoperative blood loss to less than $1,000 \mathrm{~mL}$.

Neural monitoring is a useful adjunct in preserving neurological function by the identification of functional sacral roots. The activity of the anal sphincter can be ex- trapolated to the activity of the external urethral sphincter because both are innervated by the pudendal nerve, with a root value of S2, S3, and S4. Surgeon-triggered stimulation of these nerve roots can be picked up by sphincter electrodes during surgery [33], indicating the functional status of the nerve roots and warranting their preservation. Large sacral wound defects might require myocutaneous flaps for good healing. Bilateral gluteal musculocutaneous advancement (BGMA) flaps are sufficient in primary tumors treated without radiotherapy and preserved gluteal vessels, whereas trans-pelvic ventral rectus abdominal myocutaneous (VRAM) flaps need to be considered otherwise. Free flaps are considered if VRAM flaps have been scarred by previous abdominal surgeries [34]. Five of our patients had significant dead spaces after sacral resections. Two of them (one GCT treated with total sacrectomy and one patient with a large recurrent chordoma with resection up to S1-S2) were managed by BGMA flaps performed by our plastic surgery team (Fig. 1I, J). Two were managed by a V-Y myocutaneous advancement flap. These four patients had good healing without any wound complications. One patient with a partial sacrectomy in which the dead space was not managed by a plastic procedure developed a deep wound infection and needed 

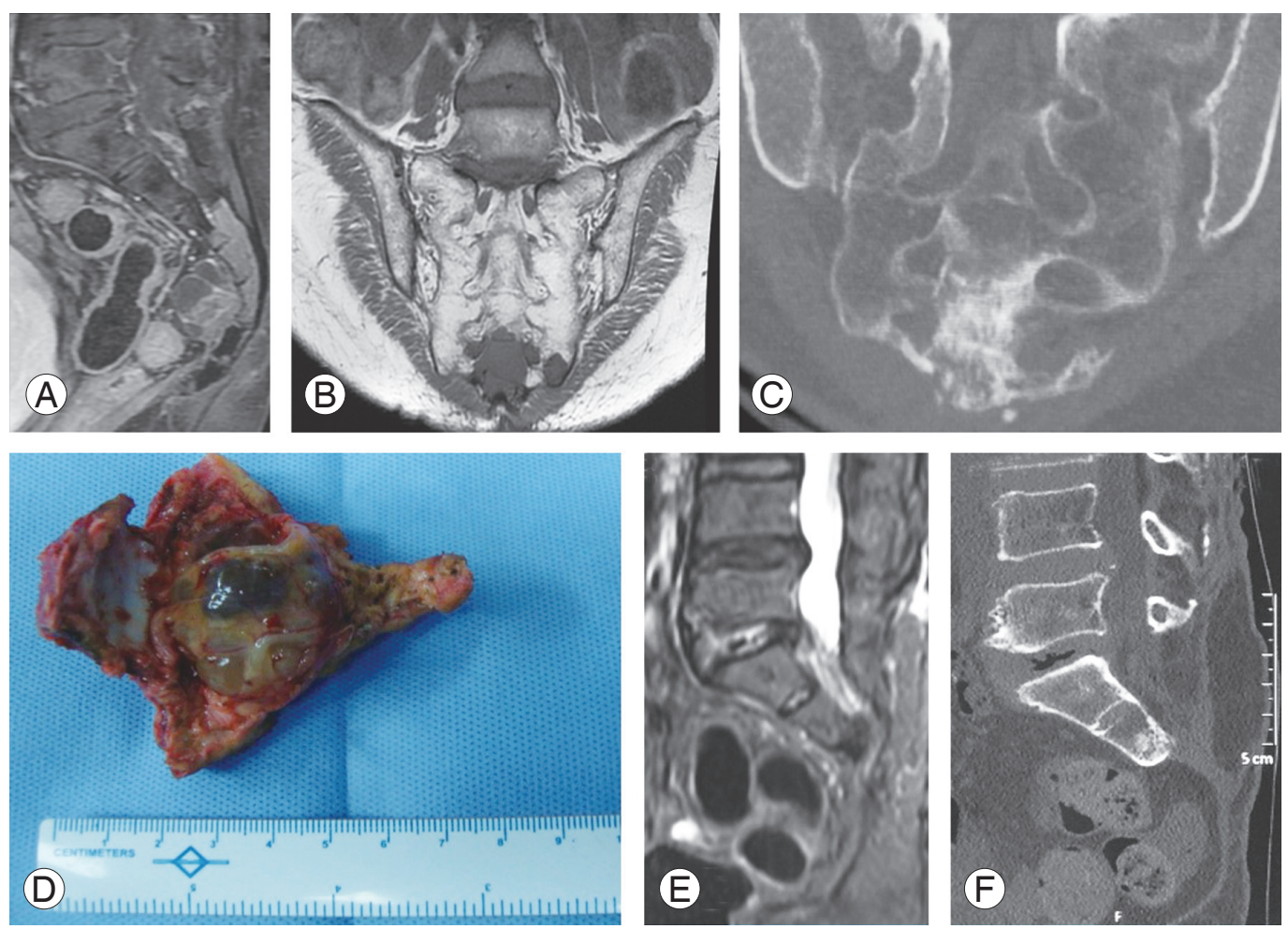

Fig. 3. (A-F) Sacral chordoma. (A, B) Preoperative sagittal and coronal magnetic resonance imaging (MRI) images showing the extent of lesion up to S3. (C) Preoperative computed tomography (CT) scan. (D) Clinical image of specimen resected by wide excision. (E, F) Follow-up MRI and CT scan at 5-year follow-up showing no disease recurrence.

wound debridement and subsequent treatment with intravenous antibiotics.

Chordomas are rare low-grade, slow-growing malignant bone tumors arising from the midline skeleton, most commonly from the sacrum. They are the most common primary sacral tumors and usually present after the fifth decade owing to their slow-growing nature and nonspecific clinical symptoms [35]. The extracompartmental extension at the time of presentation is the main predictor of the patient's life expectancy [36]. Chordomas are known to have poor sensitivity to chemotherapy and radiotherapy, making surgical resection the gold standard treatment [35]. Surgical margins are defined according to the Enneking classification system as intralesional, marginal, wide, and radical. A meta-analysis by $\mathrm{Yu}$ et al. [35] concluded that the surgical margin is the most decisive factor in achieving good disease control in sacral chordomas. Recurrence rates were lower in patients with wide surgical margins in contrast to inadequate (intralesional and marginal excision) margins [35,37]. Most of the studies report a median overall survival rate of $>5$ years, and local recurrence and metastasis contributes to morbidity and mortality in these patients [35]. DSA followed by a preoperative TAE helps reduce blood loss and the time needed for surgical resection [31]. Seven of 17 patients in our study had chordomas, constituting the majority of our patients. Five cases were primary chordomas and were treated with en bloc resection with Enneking appropriate wide margins. An example of a surgically treated primary chordoma is illustrated (Fig. 3). There has been no recurrence to date (follow-up 1.5 to 5 years). Two patients had recurrent chordomas, one of who was treated with partial sacrectomy. The margins were inadequate on histopathological examination, and the patient had a recurrence at 2-year follow-up despite radiotherapy (Fig. 4). The other recurrent case was inoperable, with a large extracompartmental lesion and intrapelvic extension, and was treated with radiotherapy. More recent advents, such as carbon ion radiotherapy, proton beam therapy, and molecular targeted therapy agents (e.g., imatinib, temsirolimus) have been promising in treating recurrent inoperable chordomas [38-40].

Schwannoma and neurofibroma are the two common benign tumors arising from intrasacral neural elements and are sometimes associated with giant presacral com- 

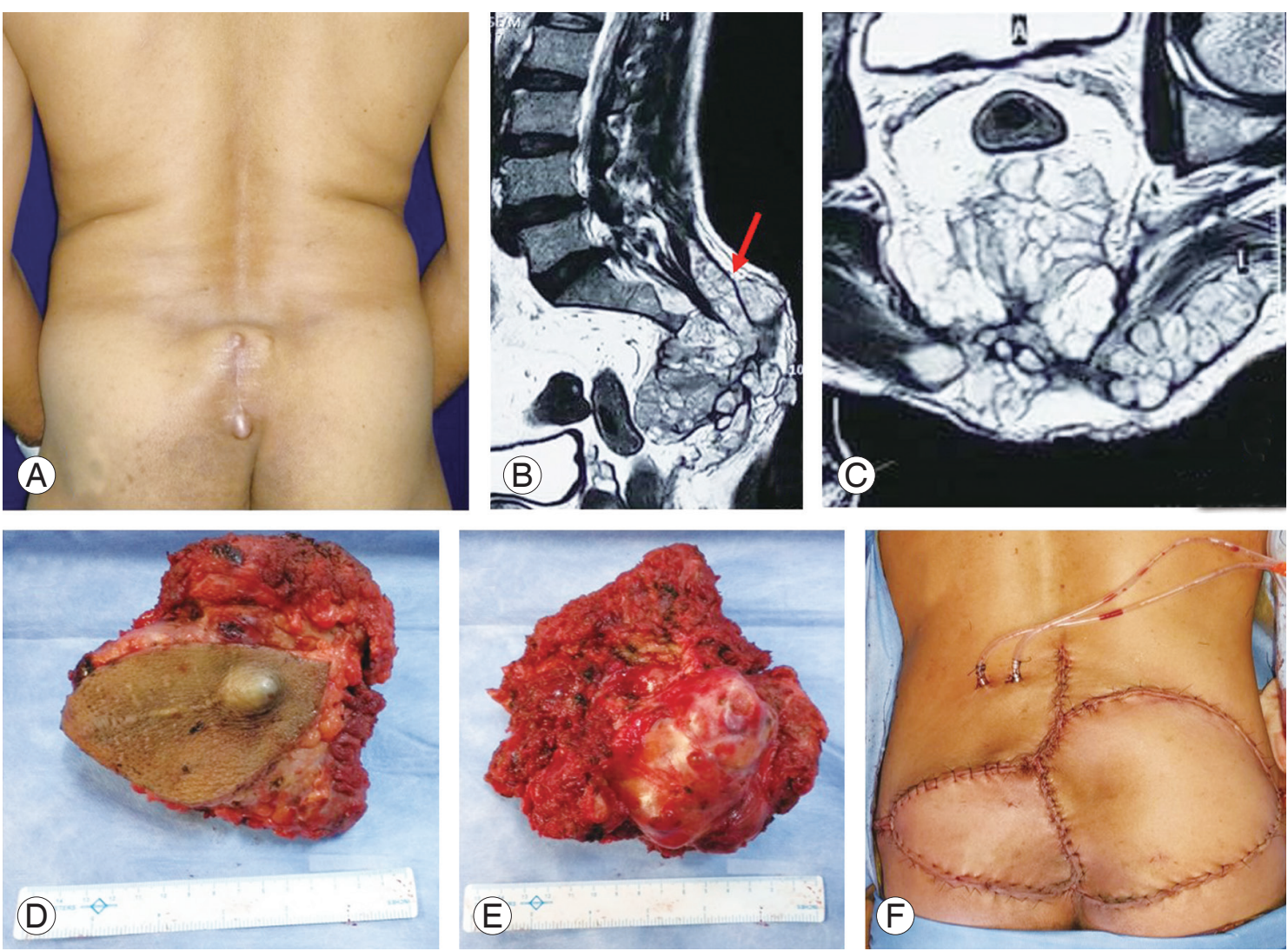

Fig. 4. (A-F) Recurrent sacral chordoma. (A) Preoperative clinical image showing invasion of the skin by local extension of recurrent tumor. (B, C) Preoperative sagittal and coronal magnetic resonance images showing recurrent sacral lesion involving up to S2 with pre-sacral and sub-cutaneous extension (red arrow). (D, E) Clinical image showing removed tumor en-bloc with the skin. (F) Intraoperative image showing closure of large skin defect by gluteus maximus advancement flap.

ponents in addition to intrasacral component. Despite the evolution of treatment strategies, surgical resection remains the optimal treatment [41]. A laminectomy is often sufficient to remove intrasacral tumors. However large presacral lesions might require partial sacral amputations: a blunt dissection of the tumor from the rectum before removing them. Owing to their benign nature, these neural tumors can be managed by marginal excision, given they have a distinct pseudo-capsule. We had two such patients with no presacral components who were managed by laminectomy/hemilaminectomy and marginal excision, taking care to preserve the sacral nerve roots using intraoperative neural monitoring. One of them is illustrated (Fig. 5). The local recurrence rate varies between $7 \%$ and $21 \%$, and no treatment might be necessary unless symptomatic [41]. The neurological symptoms resolved completely in both of our patients, with no disease recurrence at follow-up.

ES of the sacrum is a malignant tumor belonging to a group of small, round, blue cell neoplasms, differentiated from the other PNETs by neural and immune histochemical markers. They usually present in the first 2 decades of life and have an aggressive course. They are highly chemosensitive, making multiagent chemotherapy (neoadjuvant and adjuvant) the cornerstone of their treatment. Local disease control can be achieved by wide en bloc excision, radiotherapy, or both [42]. The superiority of either surgery or radiotherapy is still debated. Unlike ES of the extremities, surgery for sacral ES is complex because of the anatomy, with potential neurological compromise and inadequate margins. Although many authors advocate wide resection of the tumor as the only way of curing the disease locally $[42,43]$, surgery with inadequate margins is associated with a high recurrence rate and a poorer prognosis. Following ES resection, chemotherapy-induced tumor necrosis is an important prognostic predictive factor to evaluate the efficacy of chemotherapy. With recent advances, radiotherapy provides good local control for ES, justifying its evaluation as an alternative to surgical treat- 

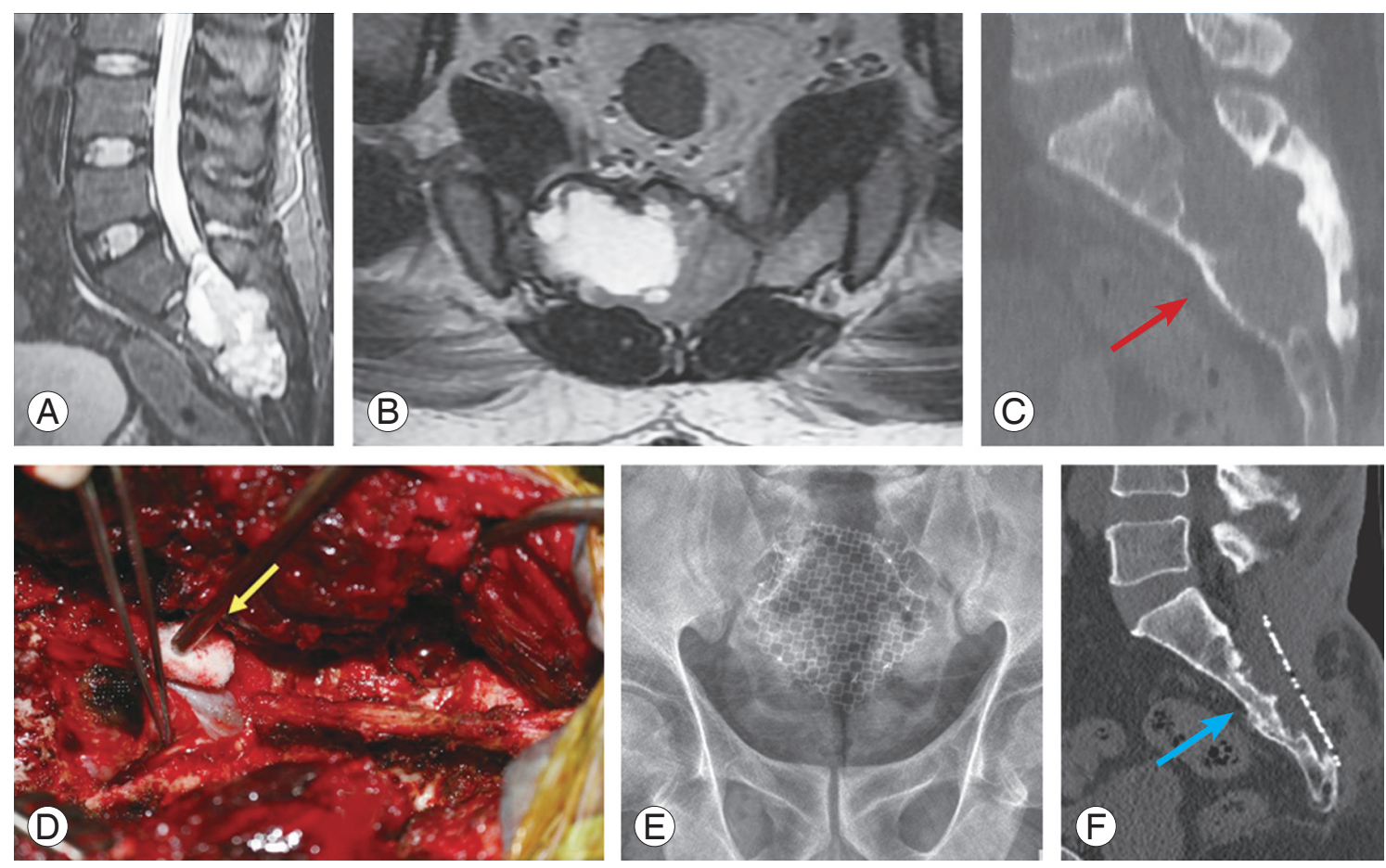

Fig. 5. (A-F) Sacral schwannoma. (A, B) Preoperative magnetic resonance images intra-sacral lesion with no pre-sacral extension. (C) Preoperative computed tomography (CT) image showing the scalloping (red arrow) of the anterior sacral cortex by the lesion. (D) Intraoperative image showing removal of tumor (yellow arrow) arising from right S3 root following laminectomy. (E) Postoperative X-ray showing laminectomy defect reconstructed using a titanium mesh. (F) Follow-up CT scan at 2 years showing re-ossification of the anterior sacral wall (blue arrow), and no recurrence.
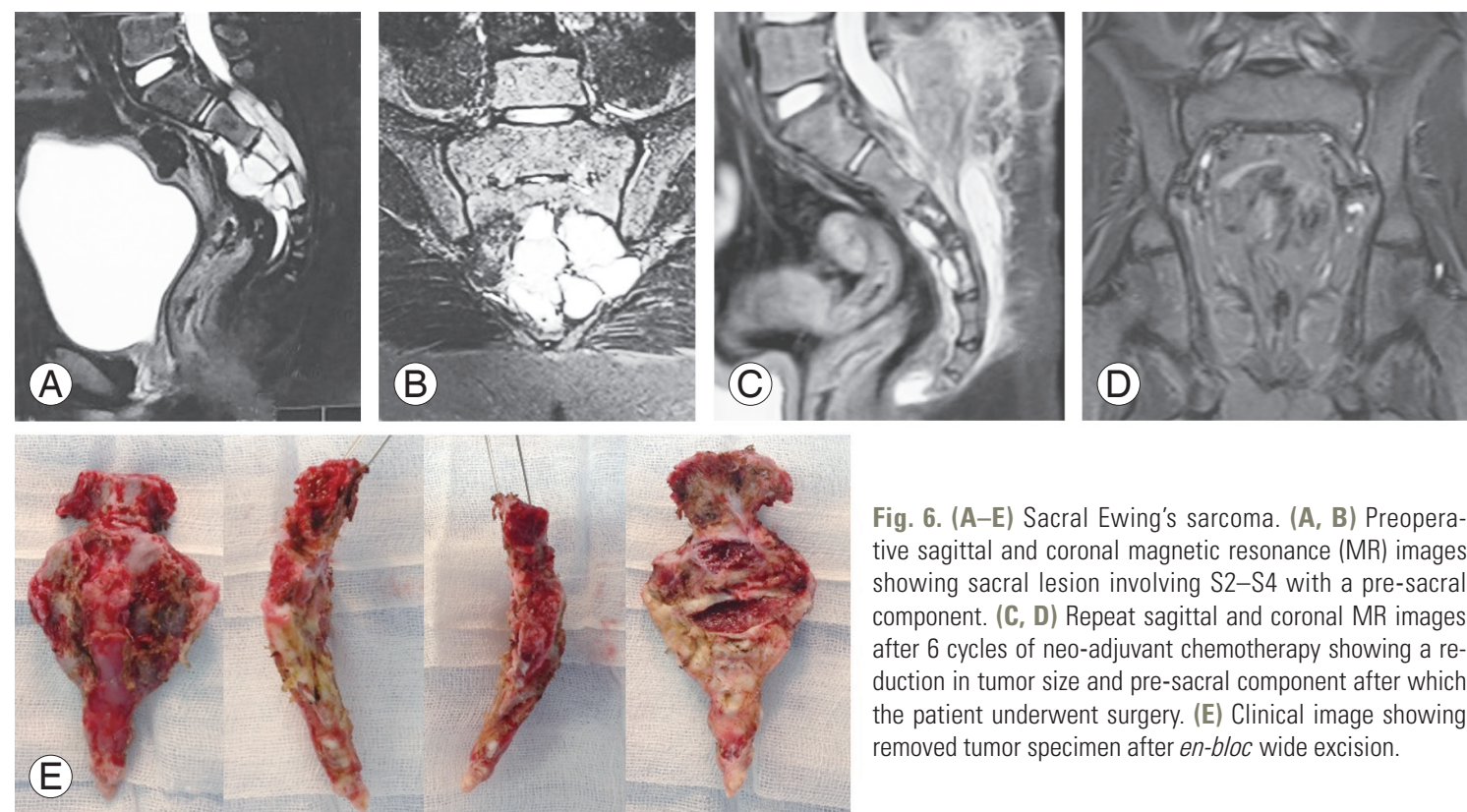

Fig. 6. (A-E) Sacral Ewing's sarcoma. (A, B) Preoperative sagittal and coronal magnetic resonance (MR) images showing sacral lesion involving $\$ 2-S 4$ with a pre-sacral component. (C, D) Repeat sagittal and coronal MR images after 6 cycles of neo-adjuvant chemotherapy showing a reduction in tumor size and pre-sacral component after which the patient underwent surgery. (E) Clinical image showing removed tumor specimen after en-bloc wide excision.

ment $[42,44,45]$. Hence, radiotherapy has a clear advantage over surgery in locally advanced tumors. We had two cases of sacral ES. One patient was an 11-year-old presenting with a large ES extending from S2 to S5, with bowel and bladder incontinence. He underwent six cycles of NAC (VAC/IE [vincristine+doxorubicin+cyclophospham ide alternating with ifosfamide+etoposide] regimen) over a 12-week period, which showed drastic shrinkage of the 

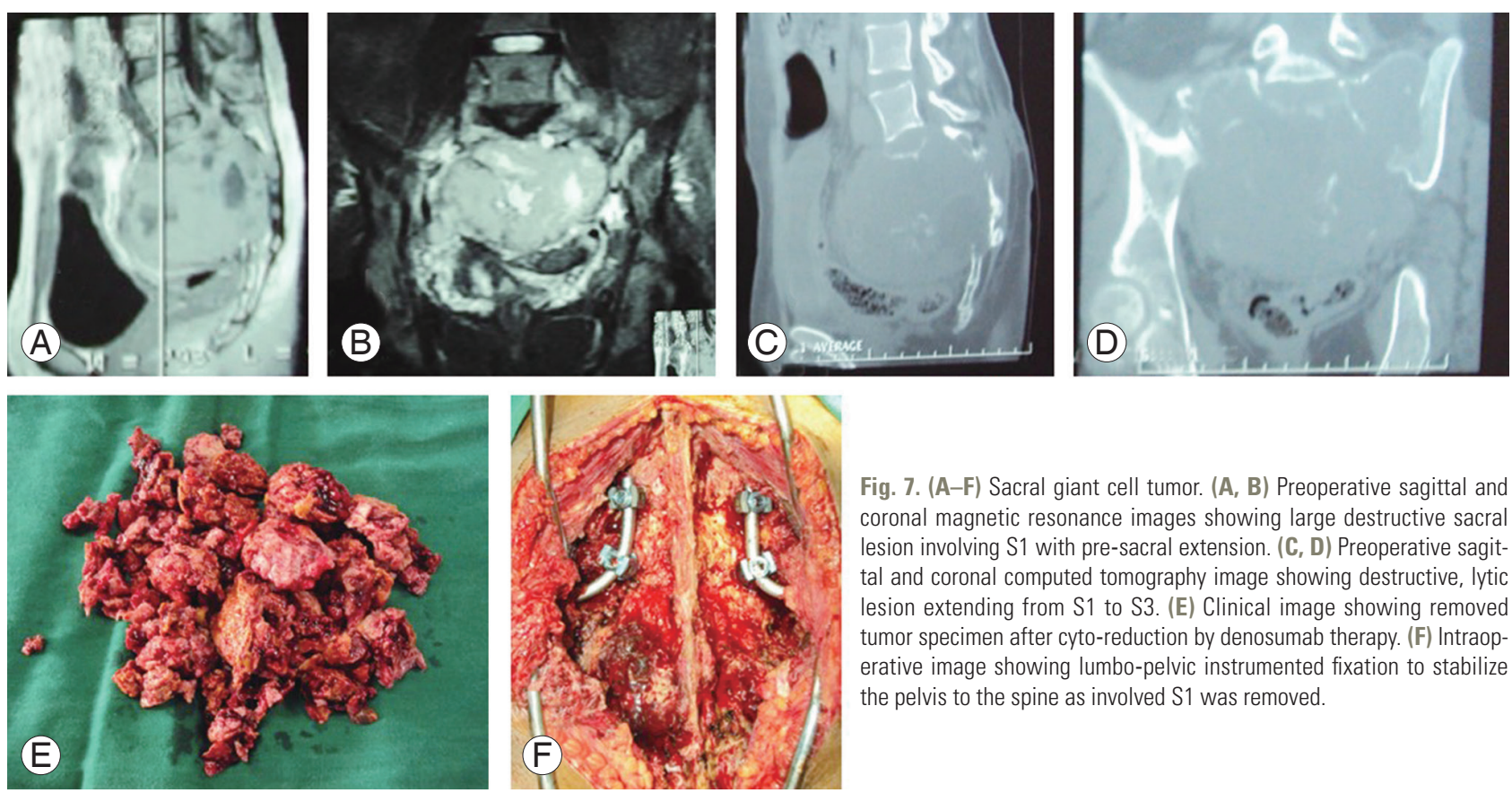

Fig. 7. (A-F) Sacral giant cell tumor. (A, B) Preoperative sagittal and coronal magnetic resonance images showing large destructive sacral lesion involving S1 with pre-sacral extension. (C, D) Preoperative sagittal and coronal computed tomography image showing destructive, lytic lesion extending from S1 to S3. (E) Clinical image showing removed tumor specimen after cyto-reduction by denosumab therapy. (F) Intraoperative image showing lumbo-pelvic instrumented fixation to stabilize the pelvis to the spine as involved S1 was removed.

tumor (by $80 \%$ ). He later underwent partial sacrectomy and adjuvant chemotherapy (Fig. 6). He regained bowel and bladder control and showed no signs of recurrence at the 1-year follow-up. Unfortunately, he succumbed to pulmonary infection and systemic sepsis later. The other patient with ES had a locally advanced tumor involving pelvic organs and was treated with chemotherapy and radiotherapy. He had no signs of local disease progression at 2-year follow-up.

GCT is the most common benign sacral tumor in the literature $[2,5,32]$. Despite being termed benign, they possess locally aggressive characteristics and can metastasize to the lung [46]. Treatment options include surgery (intralesional curettage; marginal excision; wide excision), TAE, and radiotherapy. Intralesional curettage and marginal excision in high sacral GCTs might help preserve sacroiliac joint stability but are associated with higher recurrence rates and blood loss $[32,46]$. Adjuvants such as bone cement and liquid nitrogen have been proposed to reduce recurrence with limited results [47]. Wide excision with clear margins offers the lowest recurrence rates and less blood loss at the expense of stability, given the GCTs are often large and their wide resections involve the sacroiliac joint [48]. Preoperative TAE following a DSA helps in reducing blood loss and surgical time by reducing tumor vascularity [30]. Given our patient had a lesion extending up to S1, a total sacrectomy was performed after TAE, and lumbopelvic mesh reconstruction and stabilization were necessary (Fig. 7). Isolated radiotherapy in inoperable cases has been reported, with a high recurrence rate and risk of developing radiation-induced sarcomas [49]. Serial TAE has also been shown to cause shrinkage of large GCTs, with good pain relief and disease control, and can be useful for inoperable cases [50].

One patient in our study had a mucinous cystadenocarcinoma, which is a rare malignant tumor typically arising from the ovary, colon, or pancreas. They can also arise from the soft tissue surrounding the rectum with contiguous involvement of the sacrum [51]. Such isolated sacral lesions with no distant metastasis can still be surgically resected [52]. Our patient presented with urinary dysfunction and back pain and was diagnosed based on MRI showing a large presacral mass with a destructive lesion in the sacrum, and needle biopsy confirmed the diagnosis. The metastatic workup was negative. The patient underwent partial sacrectomy, with an added anterior procedure for removal of the rectal lesion and a colostomy. Postoperative chemotherapy and radiotherapy were also administered. The patient had no recurrence at 18-month follow-up.

Primary sacral lymphomas are very rare tumors presenting as destructive lesions with or without neural involvement. These are predominantly non-Hodgkin's Bcell lymphomas (NHBL). They are highly chemo- and ra- 


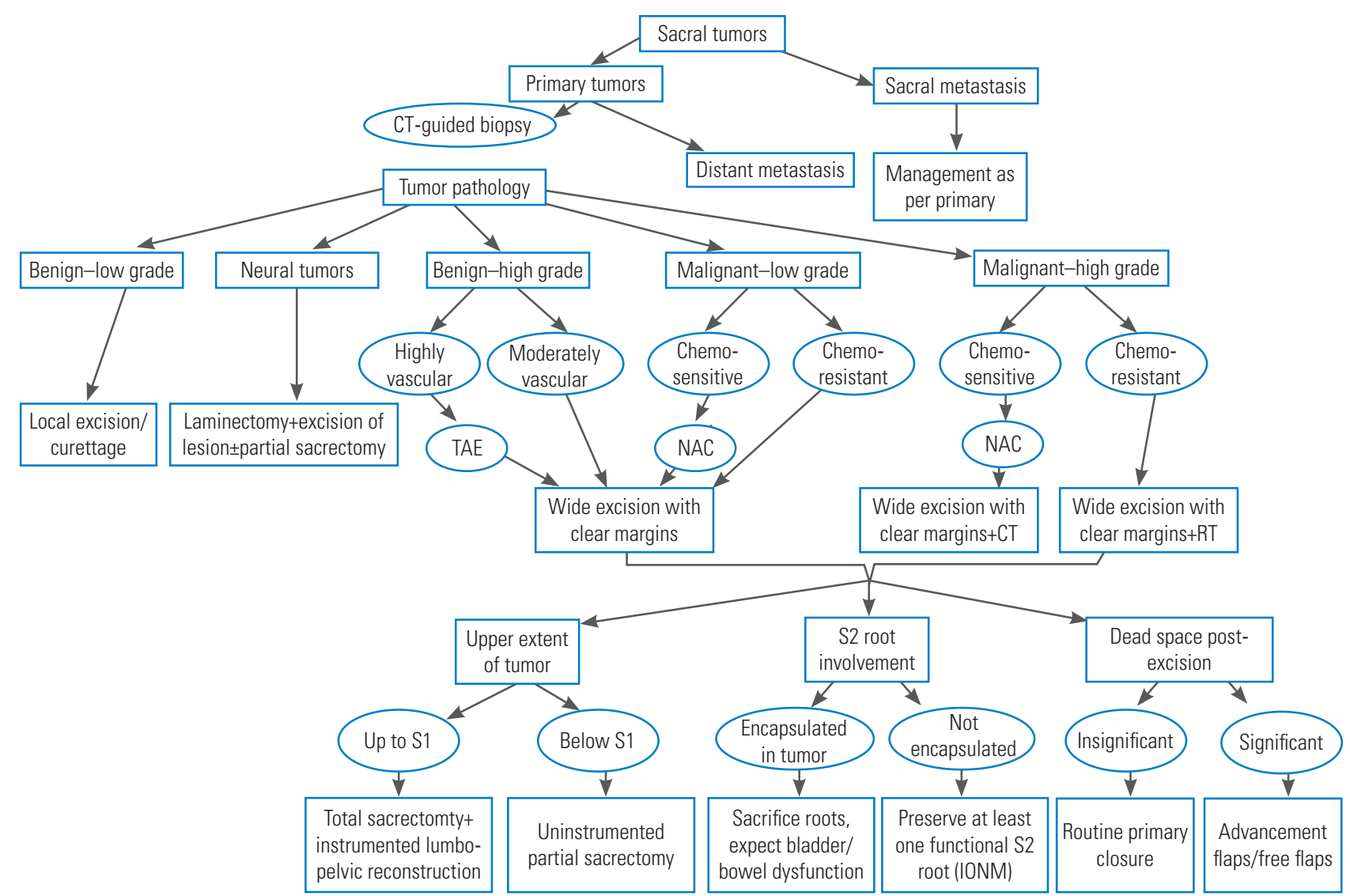

Fig. 8. Stepwise approach to manage primary sacral tumors based on our experience and literature review. CT, computed tomography; TAE, transarterial embolization; NAC, neoadjuvant chemotherapy; IONM, intraoperative neural monitoring.

diosensitive and rarely need surgical removal in instances such as severe neural dysfunction. Chemotherapy employing the chemotherapy regimen has been the standard of care. The recent advent of monoclonal antibodies such as rituximab demonstrates good disease-free survival in up to $85 \%$ of patients, especially when combined with field radiotherapy [53]. One of our sacral lesions turned out to be an NHBL and was treated by chemotherapy and radiotherapy with complete resolution of symptoms.

Based on our institutional experience and with input from the literary review, we have formulated a management algorithm to guide the investigation and treatment of primary sacral tumors (Fig. 8).

\section{Limitations}

We do recognize the limitations of our study. Being a retrospective study with a relatively small sample size, a prospective study on a larger group of patients is needed to generalize surgical outcomes. However, our recom- mended approach to any primary sacral tumor was based on our experience and a detailed review of the literature.

\section{Conclusions}

Management of primary sacral tumors needs a multidisciplinary approach comprising a team of specialists to optimize patient outcome. A stand-alone posterior approach can be used to treat most of the sacral lesions extending up to S1. An en bloc wide resection is the optimal treatment of primary malignant and aggressive benign tumors such as GCTs. Preservation of the S1 body and sacroiliac joint integrity is paramount to avoid lumbopelvic fixation. Preservation of at least one functional S2 nerve root is imperative to preserve bowel and bladder function.

\section{Conflict of Interest}

No potential conflict of interest relevant to this article was reported. 


\section{Author Contributions}

Venugopal Sarath Chander: principal investigator and article writing; Ramachandran Govindasamy; data and literature inputs; Venkata Ramakrishna Tukkapuram: data aggregation and preliminary manuscript ideas; Swaroop Gopal: consultant surgeon, valuable literary inputs; and Satish Rudrappa: clinical decisions, knowledge gap resource, and principal surgeon.

\section{References}

1. Sciubba DM, Petteys RJ, Garces-Ambrossi GL, et al. Diagnosis and management of sacral tumors. J Neurosurg Spine 2009;10:244-56.

2. Varga PP, Bors I, Lazary A. Sacral tumors and management. Orthop Clin North Am 2009;40:105-23.

3. Varga PP, Szoverfi Z, Lazary A. Surgical treatment of primary malignant tumors of the sacrum. Neurol Res 2014;36:577-87.

4. Puri A, Agarwal MG, Shah M, et al. Decision making in primary sacral tumors. Spine J 2009;9:396-403.

5. Wang J, Li D, Yang R, Tang X, Yan T, Guo W. Epidemiological characteristics of 1385 primary sacral tumors in one institution in China. World J Surg Oncol 2020;18:297.

6. Biagini R, Ruggieri P, Mercuri M, et al. Neurologic deficit after resection of the sacrum. Chir Organi Mov 1997;82:357-72.

7. Thornton E, Krajewski KM, O'Regan KN, Giardino AA, Jagannathan JP, Ramaiya N. Imaging features of primary and secondary malignant tumours of the sacrum. Br J Radiol 2012;85:279-86.

8. Safaee MM, Carrera DA, Chin CT, et al. Diagnostic challenges in primary sacral tumors and the yield of computed tomography-guided needle biopsy in the modern era. World Neurosurg 2020;138:e806-18.

9. Clarke MJ, Dasenbrock H, Bydon A, et al. Posterioronly approach for en bloc sacrectomy: clinical outcomes in 36 consecutive patients. Neurosurgery 2012;71:357-64.

10. Sar C, Eralp L. Surgical treatment of primary tumors of the sacrum. Arch Orthop Trauma Surg 2002;122:148-55.

11. Simpson AH, Porter A, Davis A, Griffin A, McLeod RS, Bell RS. Cephalad sacral resection with a combined extended ilioinguinal and posterior approach.
J Bone Joint Surg Am 1995;77:405-11.

12. Gennari LE, Azzarelli AL, Quagliuolo VI. A posterior approach for the excision of sacral chordoma. J Bone Joint Surg Br 1987;69:565-8.

13. Waisman M, Kligman M, Roffman M. Posterior approach for radical excision of sacral chordoma. Int Orthop 1997;21:181-4.

14. Asavamongkolkul A, Waikakul S. Wide resection of sacral chordoma via a posterior approach. Int Orthop 2012;36:607-12.

15. McLoughlin GS, Sciubba DM, Suk I, et al. En bloc total sacrectomy performed in a single stage through a posterior approach. Neurosurgery 2008;63(1 Suppl 1):ONS115-20.

16. Zang J, Guo W, Yang R, Tang X, Li D. Is total en bloc sacrectomy using a posterior-only approach feasible and safe for patients with malignant sacral tumors? J Neurosurg Spine 2015;22:563-70.

17. Fourney DR, Rhines LD, Hentschel SJ, et al. En bloc resection of primary sacral tumors: classification of surgical approaches and outcome. J Neurosurg Spine 2005;3:111-22.

18. Hugate RR Jr, Dickey ID, Phimolsarnti R, Yaszemski MJ, Sim FH. Mechanical effects of partial sacrectomy: when is reconstruction necessary? Clin Orthop Relat Res 2006;450:82-8.

19. Sung HW, Shu WP, Wang HM, Yuai SY, Tsai YB. Surgical treatment of primary tumors of the sacrum. Clin Orthop Relat Res 1987:91-8.

20. Moran D, Zadnik PL, Taylor T, et al. Maintenance of bowel, bladder, and motor functions after sacrectomy. Spine J 2015;15:222-9.

21. Cheng EY, Ozerdemoglu RA, Transfeldt EE, Thompson RC Jr. Lumbosacral chordoma: prognostic factors and treatment. Spine (Phila Pa 1976) 1999;24:163945.

22. Todd LT Jr, Yaszemski MJ, Currier BL, Fuchs B, Kim CW, Sim FH. Bowel and bladder function after major sacral resection. Clin Orthop Relat Res 2002:36-9.

23. Gunterberg B. Effects of major resection of the sacrum: clinical studies on urogenital and anorectal function and a biomechanical study on pelvic strength. Acta Orthop Scand Suppl 1976;162:1-38.

24. Bergh P, Kindblom LG, Gunterberg B, Remotti F, Ryd W, Meis-Kindblom JM. Prognostic factors in chordoma of the sacrum and mobile spine: a study of 39 patients. Cancer 2000;88:2122-34. 
25. Guo Y, Palmer JL, Shen L, et al. Bowel and bladder continence, wound healing, and functional outcomes in patients who underwent sacrectomy. J Neurosurg Spine 2005;3:106-10.

26. Zoccali C, Skoch J, Patel AS, Walter CM, Maykowski P, Baaj AA. Residual neurological function after sacral root resection during en-bloc sacrectomy: a systematic review. Eur Spine J 2016;25:3925-31.

27. Stener B, Gunterberg B. High amputation of the sacrum for extirpation of tumors: principles and technique. Spine (Phila Pa 1976) 1978;3:351-66.

28. Fujimura Y, Maruiwa H, Takahata T, Toyama Y. Neurological evaluation after radical resection of sacral neoplasms. Paraplegia 1994;32:396-406.

29. Andreoli F, Balloni F, Bigiotti A, et al. Anorectal continence and bladder function: effects of major sacral resection. Dis Colon Rectum 1986;29:647-52.

30. Yang HL, Chen KW, Wang GL, et al. Pre-operative transarterial embolization for treatment of primary sacral tumors. J Clin Neurosci 2010;17:1280-5.

31. Yang H, Zhu L, Ebraheim NA, et al. Surgical treatment of sacral chordomas combined with transcatheter arterial embolization. J Spinal Disord Tech 2010;23:47-52.

32. Martin C, McCarthy EF. Giant cell tumor of the sacrum and spine: series of 23 cases and a review of the literature. Iowa Orthop J 2010;30:69-75.

33. James HE, Mulcahy JJ, Walsh JW, Kaplan GW. Use of anal sphincter electromyography during operations on the conus medullaris and sacral nerve roots. Neurosurgery 1979;4:521-3.

34. Miles WK, Chang DW, Kroll SS, et al. Reconstruction of large sacral defects following total sacrectomy. Plast Reconstr Surg 2000;105:2387-94.

35. Yu X, Kou C, Bai W, et al. Comparison of wide margin and inadequate margin for recurrence in sacral chordoma: a meta-analysis. Spine (Phila Pa 1976) 2020;45:814-9.

36. Boriani S, Bandiera S, Biagini R, et al. Chordoma of the mobile spine: fifty years of experience. Spine (Phila Pa 1976) 2006;31:493-503.

37. Kaiser TE, Pritchard DJ, Unni KK. Clinicopathologic study of sacrococcygeal chordoma. Cancer 1984;53:2574-8.

38. Park L, Delaney TF, Liebsch NJ, et al. Sacral chordomas: impact of high-dose proton/photon-beam radiation therapy combined with or without surgery for primary versus recurrent tumor. Int J Radiat Oncol Biol Phys 2006;65:1514-21.

39. Meng T, Jin J, Jiang C, et al. Molecular targeted therapy in the treatment of chordoma: a systematic review. Front Oncol 2019;9:30.

40. Imai $\mathrm{R}$, Kamada $\mathrm{T}$, Tsuji $\mathrm{H}$, et al. Carbon ion radiotherapy for unresectable sacral chordomas. Clin Cancer Res 2004;10:5741-6.

41. Zang J, Guo W, Yang Y, Wei R. Surgical treatment of giant benign sacral neurogenic tumors using the posterior-only approach. Clin Neurol Neurosurg 2019;185:105483.

42. Angelini A, Letson DG, Ruggieri P. Ewing's sarcoma of the sacrum. In: Ruggieri P, Angelini A, Vanel D, Picci P, editors. Tumors of the sacrum: diagnosis and treatment of benign and malignant tumors. Cham: Springer International Publishing; 2017. p. 221-6.

43. Wuisman P, Lieshout O, Sugihara S, van Dijk M. Total sacrectomy and reconstruction: oncologic and functional outcome. Clin Orthop Relat Res 2000:192203.

44. Indelicato DJ, Keole SR, Shahlaee AH, et al. Spinal and paraspinal Ewing tumors. Int J Radiat Oncol Biol Phys 201;76:1463-71.

45. Hesla AC, Tsagozis P, Jebsen N, Zaikova O, Bauer $\mathrm{H}$, Brosjo O. Improved prognosis for patients with Ewing sarcoma in the sacrum compared with the innominate bones: the Scandinavian Sarcoma Group experience. J Bone Joint Surg Am 2016;98:199-210.

46. Luksanapruksa P, Buchowski JM, Singhatanadgige W, Bumpass DB. Systematic review and meta-analysis of en bloc vertebrectomy compared with intralesional resection for giant cell tumors of the mobile spine. Global Spine J 2016;6:798-803.

47. Marcove RC, Sheth DS, Brien EW, Huvos AG, Healey $\mathrm{JH}$. Conservative surgery for giant cell tumors of the sacrum: the role of cryosurgery as a supplement to curettage and partial excision. Cancer 1994;74:125360.

48. Gunterberg B, Romanus B, Stener B. Pelvic strength after major amputation of the sacrum: an exerimental study. Acta Orthop Scand 1976;47:635-42.

49. Leggon RE, Zlotecki R, Reith J, Scarborough MT. Giant cell tumor of the pelvis and sacrum: 17 cases and analysis of the literature. Clin Orthop Relat Res 2004:196-207.

50. Hosalkar HS, Jones KJ, King JJ, Lackman RD. Se- 
rial arterial embolization for large sacral giant-cell tumors: mid- to long-term results. Spine (Phila Pa 1976) 2007;32:1107-15.

51. Connelly JH, Robey-Cafferty SS, Cleary KR. Mucinous carcinomas of the colon and rectum: an analysis of 62 stage B and C lesions. Arch Pathol Lab Med 1991;115:1022-5.
52. Bozkurt M, Okutur K, Aydin K, et al. Locally metastatic mucinous rectal adenocarcinoma: imaging diagnosis with DW-MRI in comparison with PET-CT. Oncol Lett 2012;3:1311-3.

53. Liu JK, Kan P, Schmidt MH. Diffuse large B-cell lymphoma presenting as a sacral tumor: report of two cases. Neurosurg Focus 2003;15:E10. 